\title{
Evaluating the Potential Impact of a Gas Pipeline on Whimbrel Breeding Habitat in the Outer Mackenzie Delta, Northwest Territories
}

\section{Évaluation de l'impact potentiel d'un gazoduc sur l'habitat de nidification du Courlis corlieu dans la partie externe du delta du Mackenzie, Territoires du Nord-Ouest}

\author{
$\underline{\text { Lisa D. Pirie }}^{1,2}$ Charles M. Francis $^{1,2}$, and Victoria H. Johnston $^{2}$
}

\begin{abstract}
We used ground surveys to identify breeding habitat for Whimbrel (Numenius phaeopus) in the outer Mackenzie Delta, Northwest Territories, and to test the value of high-resolution IKONOS imagery for mapping additional breeding habitat in the Delta. During ground surveys, we found Whimbrel nests $(n$ $=28$ ) in extensive areas of wet-sedge low-centered polygon (LCP) habitat on two islands in the Delta (Taglu and Fish islands) in 2006 and 2007. Supervised classification using spectral analysis of IKONOS imagery successfully identified additional areas of wet-sedge habitat in the region. However, ground surveys to test this classification found that many areas of wet-sedge habitat had dense shrubs, no standing water, and/or lacked polygon structure and did not support breeding Whimbrel. Visual examination of the IKONOS imagery was necessary to determine which areas exhibited LCP structure. Much lower densities of nesting Whimbrel were also found in upland habitats near wetlands. We used habitat maps developed from a combination of methods, to perform scenario analyses to estimate the potential effects of the Mackenzie Gas Project on Whimbrel habitat. Assuming effective complete habitat loss within $20 \mathrm{~m}, 50 \mathrm{~m}$, or $250 \mathrm{~m}$ of any infrastructure or pipeline, the currently proposed pipeline development would result in loss of $8 \%$, $12 \%$, or $30 \%$ of existing Whimbrel habitat. If subsidence were to occur, most Whimbrel habitat could become unsuitable. If the facility is developed, follow-up surveys will be required to test these models.
\end{abstract}

RÉSUMÉ. Nous avons effectué des relevés au sol afin de déterminer l'habitat de nidification du Courlis corlieu (Numenius phaeopus) dans la partie externe du delta du Mackenzie, Territoires du Nord-Ouest, et d'évaluer l'utilité des images IKONOS à haute résolution pour cartographier d'autres milieux de nidification dans le delta. Au cours des relevés au sol, nous avons trouvé des nids de courlis $(\mathrm{n}=28)$ dans de vastes milieux de polygones à centre concave et à carex sur deux îles (Taglu et Fish) du delta en 2006 et 2007. La classification dirigée à partir de l'analyse spectrale des images IKONOS a permis d'identifier, avec succès, d'autres cariçaies dans la région. Toutefois, les relevés au sol effectués dans le but de valider cette classification ont permis de constater que de nombreuses cariçaies comportaient des zones denses d'arbustes, ne présentaient pas de mares ni de structures polygonales et n'hébergeaient pas de courlis nicheurs. Il a été nécessaire de faire un examen visuel des images IKONOS pour déterminer quels endroits présentaient des structures polygonales. Des densités beaucoup plus faibles de courlis ont également été trouvées dans les hautes-terres adjacentes aux milieux humides. Nous avons utilisé des cartes d'habitat conçues à partir d'une combinaison de méthodes afin d'analyser des scénarios destinés à estimer les effets potentiels du projet de gazoduc du Mackenzie sur l'habitat du courlis. Si on suppose que l'habitat est entièrement détruit dans les 20,50 ou $250 \mathrm{~m}$ de toute infrastructure ou du pipeline, la construction du pipeline, tel que proposée actuellement, mènerait à la perte de 8,12 ou $30 \%$ de l'habitat du courlis. Si un

\footnotetext{
${ }^{1}$ Department of Biology, Carleton University, ${ }^{2}$ Canadian Wildlife Service,
} Environment Canada

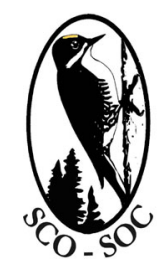

Sponsored by the Society of Canadian Ornithologists and Bird Studies Canada Parrainée par la Société des ornithologistes du Canada et Etudes d'oiseaux Canada

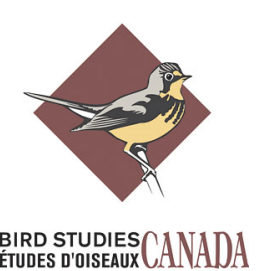


affaissement du sol survenait, une très grande proportion de l'habitat du courlis pourrait ne plus être favorable à la nidification de l'espèce. Enfin, si le gazoduc est construit, le suivi des impacts devra être effectué afin de tester ces scénarios.

Key Words: breeding ecology; breeding habitat; gas pipeline; IKONOS; Numenius phaeopus; predictive habitat modeling; remote sensing; supervised classification

\section{INTRODUCTION}

Conservation of long-distance migratory shorebirds requires protection of suitable habitat to meet their requirements at all stages of their life cycle, including on their arctic breeding grounds. The Canadian Arctic provides breeding grounds for most species of North American shorebirds (Godfrey 1986, Gratto-Trevor 1996, Morrison 2001; C. L. Gratto-Trevor unpublished report). The populations of many of these shorebird species are exhibiting widespread declines (Gould 1988, Pattie 1990, Gratto-Trevor 1994, Gratto-Trevor et al. 1998, 2001, Johnston et al. 2000, Brown et al. 2001, Morrison 2001; C. L. Gratto-Trevor unpublished report). Much conservation effort has focused on staging and wintering areas that support large concentrations of shorebirds (Paehlke 1995). However, with anticipated changes to habitat due to climate change (Morrison 2001) and increasing development pressure in the North, breeding grounds in the Arctic could become a limiting factor.

The Mackenzie Delta, in the Northwest Territories (Fig. 1) is recognized as a key terrestrial habitat for migratory birds (Latour et al. 2008), but is currently threatened with development. Previous studies have found high densities of several species of breeding shorebirds in the Delta (Tarves 1987, Dickson and Smith 1991, Gratto-Trevor 1996; H. L. Dickson et al., unpublished report; C. L. Gratto-Trevor, unpublished report; D. Jaques, unpublished reports). The Delta is the site of the proposed Mackenzie Gas Project (MGP), which is currently undergoing environmental assessment. Approval of the MGP could result in habitat loss for nesting shorebirds, particularly in the Kendall Island Bird Sanctuary (KIBS; Fig. 2). Taglu Island, in KIBS, which contains high densities of shorebirds, is the site of one of the three proposed onshore gasprocessing facilities (Fig. 3). Development and operation could affect nesting shorebirds through direct loss of breeding habitat due to construction, indirect loss of habitat resulting from conversion of habitat to other habitat types through changes in water level or water flow, disturbance due to human activities, or deterioration of habitat from contamination, oil spills, or subsidence.

Whimbrel (Numenius phaeopus; Fig. 4), a species of shorebird that breeds in low densities across the Canadian Arctic in a variety of landscapes (Skeel and Mallory 1996), is likely to be affected by MGP development. It is listed as a "Sensitive Species" in the Northwest Territories (Johnston and Carrière 2006). It has also been identified by both the U.S. and Canadian Shorebird Conservation Plans as a species of high conservation concern (Donaldson et al. 2000, Brown et al. 2001; U.S. Shorebird Conservation Plan, unpublished report).

Suitable habitats for Whimbrel and other shorebirds appear to be patchily distributed and spread over large distances, but use of remote-sensing data (such as satellite imagery) may enhance efforts to map these habitats. Previous habitat classification studies using Landsat Thematic Mapper ${ }^{\circledR}$ (TM) imagery to evaluate shorebird habitats in the Arctic had limited success. Habitat classifications developed using imagery from one region were not necessarily suitable in other regions because differing vegetation patterns, moisture regimes, landforms, and geological substrates produce different spectral responses in satellite imagery (Morrison 1997). Also, the 30-m spatial resolution of Landsat TM imagery (Gratto-Trevor 1996, Morrison 1997; C. L. Gratto-Trevor, unpublished report) cannot adequately resolve some habitat features such as low-centered polygon (LCP) ridges and raised mounds, which are often important habitat characteristics for several shorebird species (H. L. Dickson et al., unpublished report). The higher spatial resolution afforded by IKONOS® satellite imagery may improve the accuracy of mapping. 
Fig. 1. Map showing the location of the Mackenzie Delta in the Northwest Territories. The red outline represents the approximate boundaries of the Kendall Island Bird Sanctuary, which is shown in more detail in Fig. 2.

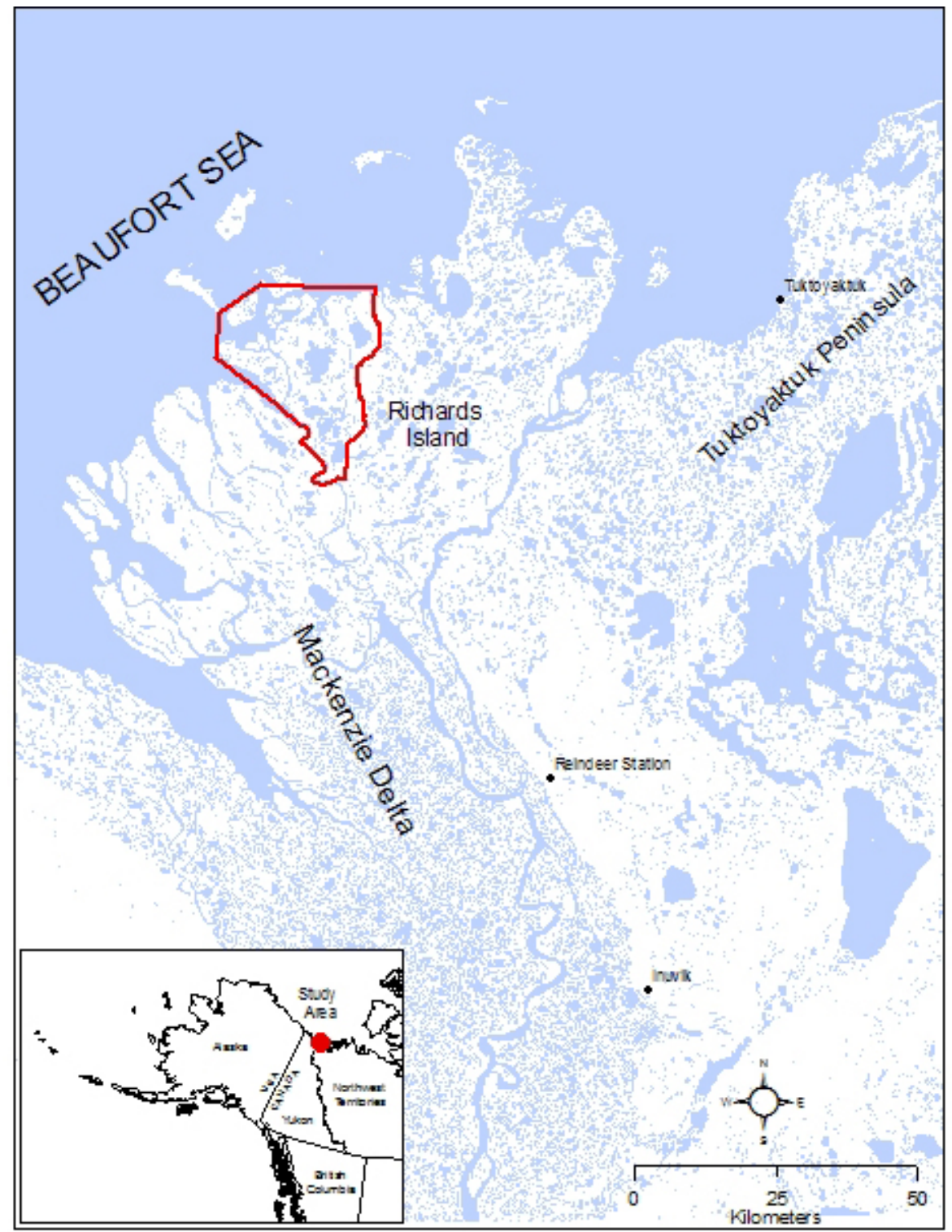

Identifying specific breeding habitat requirements and mapping the extent of available habitat for Whimbrel or other shorebirds can then be used to estimate quantitatively the potential impact of developments such as MGP. Scenario analyses provide a systematic way of making predictions regarding the impacts of proposed developments
(Mohren 2003). Habitat maps, once developed, can be used in conjunction with models of projected changes in ecosystem structure and function to develop these scenario analyses. Scenario analyses that predict the impact of MGP construction and facility operations on breeding habitat can also be used to predict the potential value of modifications 
Fig. 2. A false-color satellite image of Taglu and Fish Islands (labeled) in the Kendall Island Bird Sanctuary, outer Mackenzie Delta, Northwest Territories. The red outline indicates the boundaries of the sanctuary.

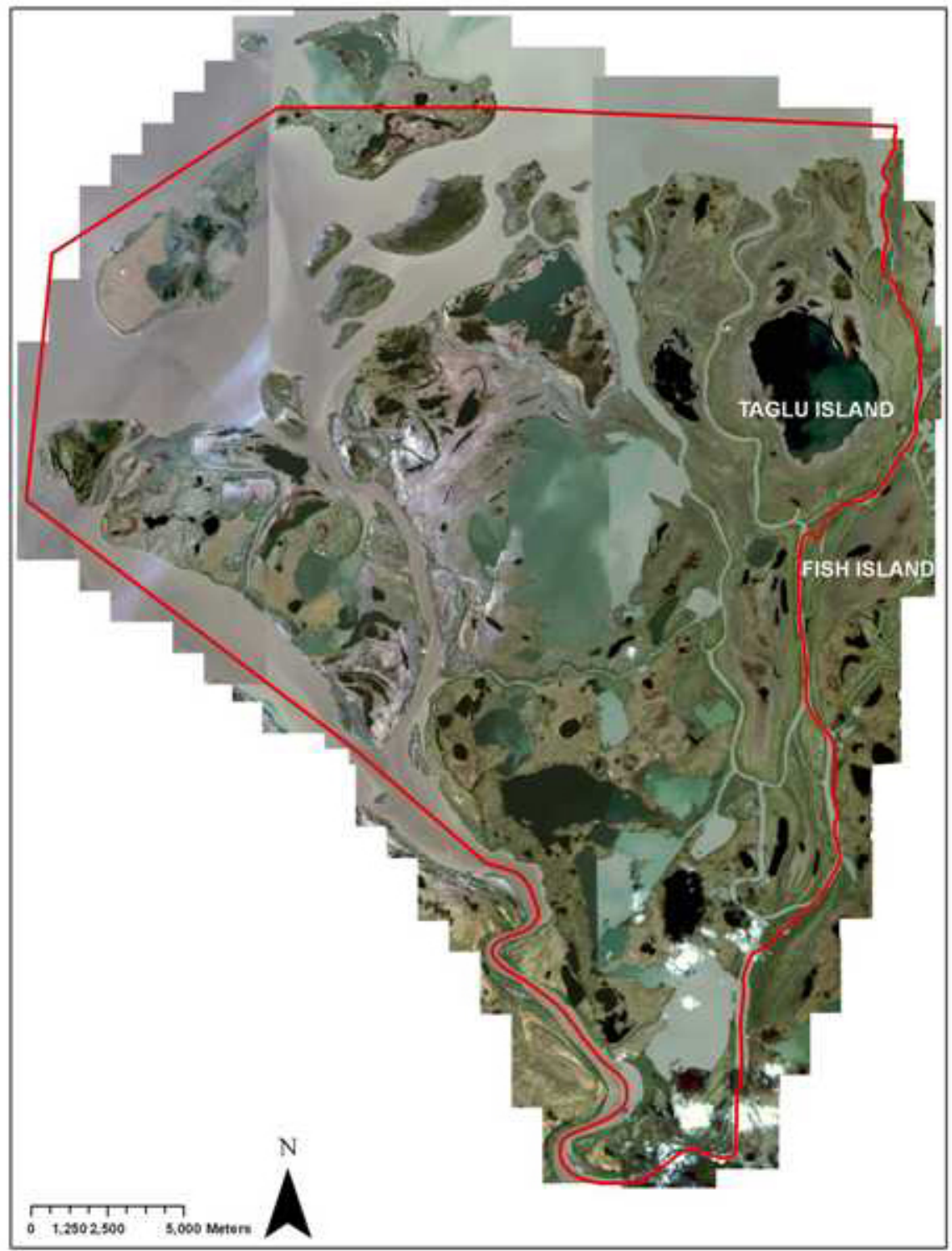

to the MGP to mitigate its impact on shorebird populations.

The objectives of our study were: (1) to identify Whimbrel breeding habitat in selected study areas in the outer Mackenzie Delta through ground studies; (2) to evaluate whether we could use remote-sensing data to identify additional Whimbrel breeding habitat in the outer Mackenzie Delta; and (3) to use a habitat map developed from a combination of methods to predict the potential impact of MGP development on Whimbrel breeding habitat under different disturbance scenarios. 
Fig. 3. The proposed Taglu Island gas-processing facility (pink outline) and proposed pipeline (gray line) for the Mackenzie Gas Project, wet-sedge low-centered polygon habitat (purple crosshatch), and the Kendall Island Bird Sanctuary boundary between Taglu and Fish Islands in the outer Mackenzie Delta, Northwest Territories.

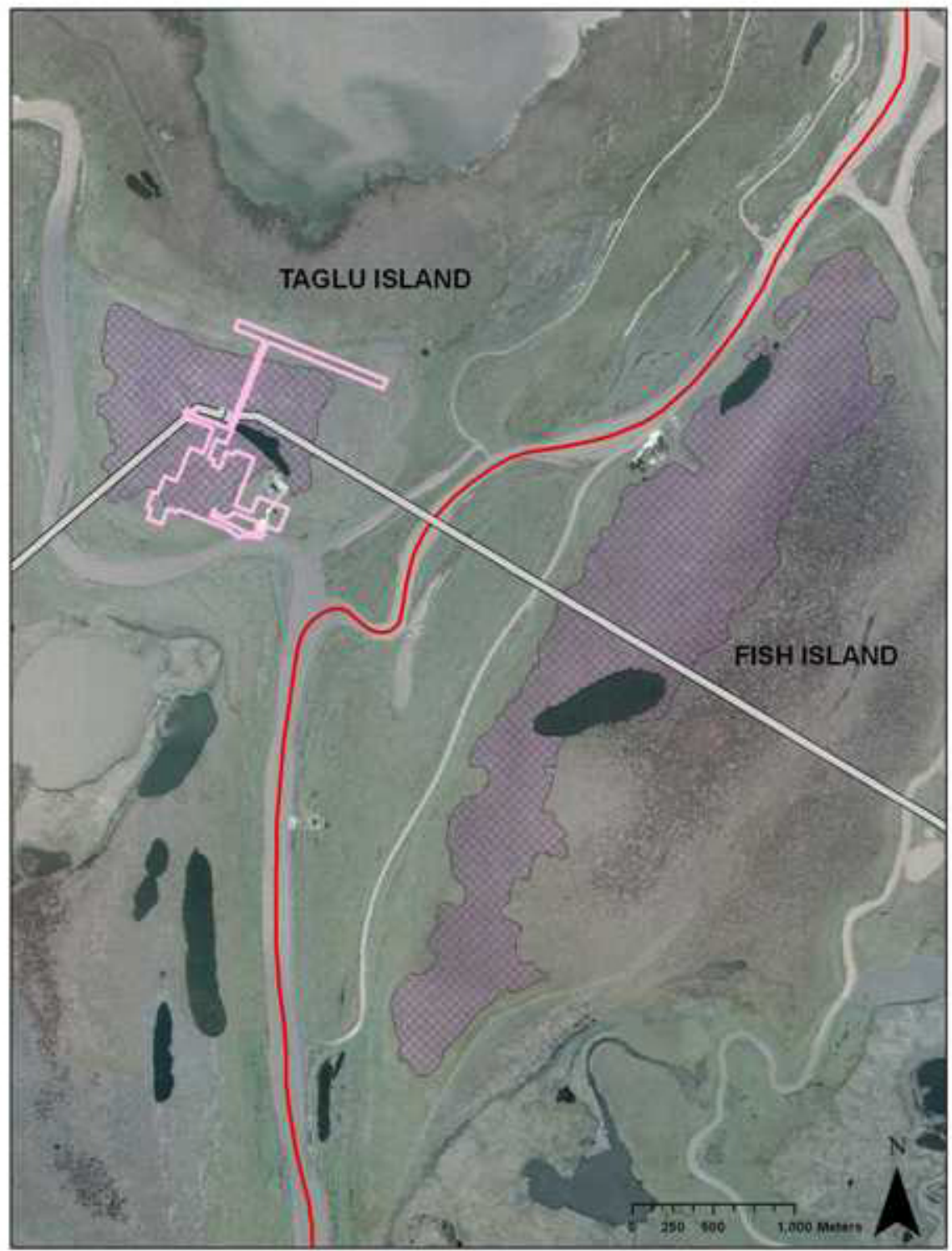


Fig. 4. A breeding adult Whimbrel (Numenius phaeopus) in the outer Mackenzie Delta, Northwest Territories. Photo by Krista Sittler (2007).

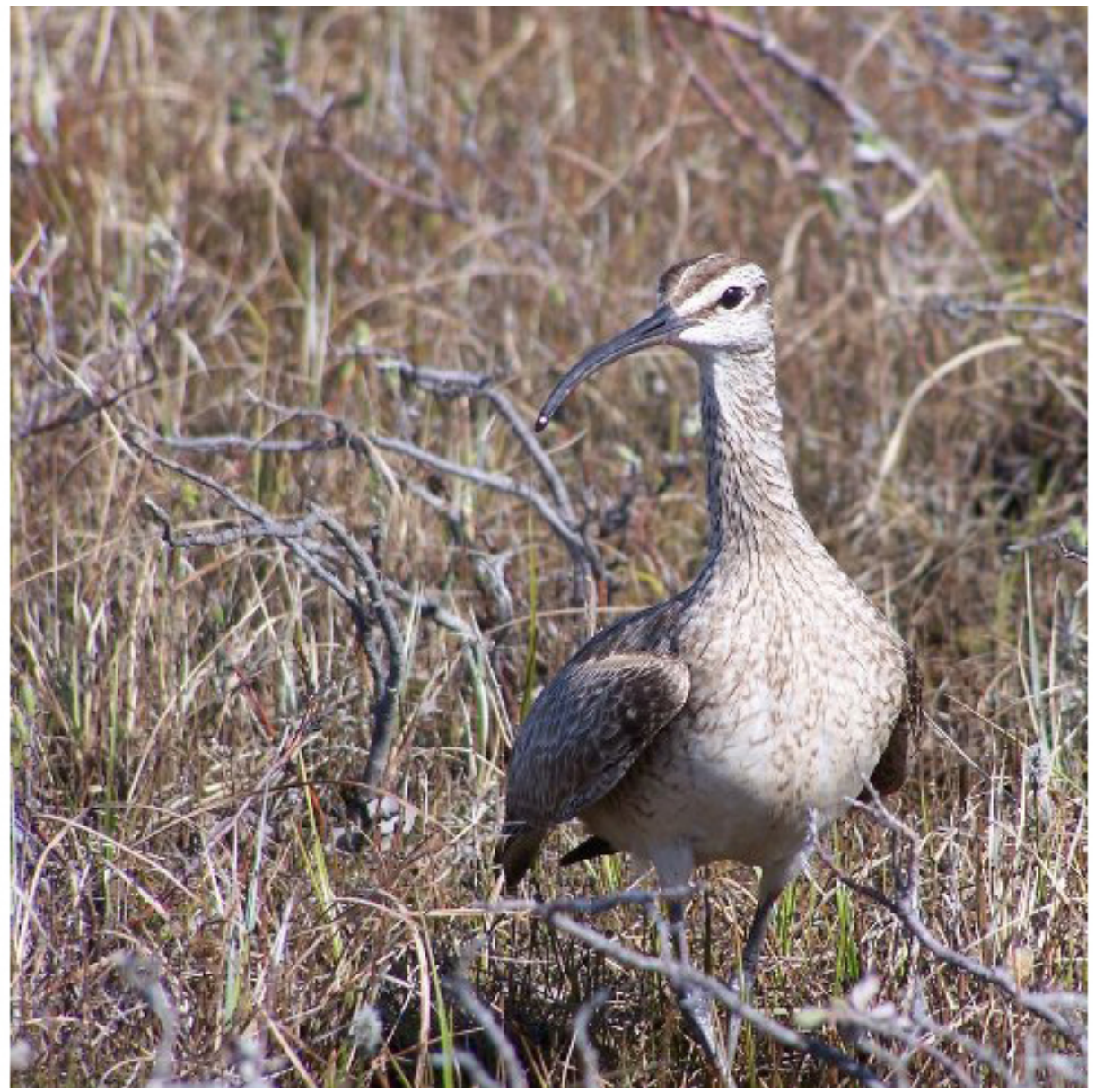

\section{METHODS}

\section{Study Area}

Our area of study encompassed the 62 300-ha KIBS and adjacent Fish Island within the outer Mackenzie River Delta (765 000 ha), east of Mackenzie Bay, bordering the Beaufort Sea Coast (Figs. 1, 2). The Canadian Wildlife Service (CWS) established KIBS in 1961 to provide long-term protection for migratory birds and their key habitats (Latour et al. 2008). The Mackenzie Delta is a subdivision of the Arctic Coastal Plain Region and is characterized by a mosaic of low-lying, alluvial islands dominated by wetlands with relatively saturated soils (Kemper 2006).
Wetlands in the Mackenzie Delta are composed of a combination of patterned and non-patterned ground. Arctic wetland areas with poor drainage commonly exhibit patterned ground (low- or highcentered polygon structures; Ritchie 1984) dominated by hydrophilic graminoids (Carex sp.), Equisetum, and Salix. Low-centered polygon habitat is caused by the development of ice wedges around which the ground is pushed up forming a raised polygonal ridge trapping water inside. Highcentered polygons are formed by the eventual increase in plant material, which causes the water flow to reverse and run off into troughs bordering the polygons. Annual spring flooding deposits nutrient-rich sediments in the wetlands, and the warm river water melts the remaining snow, 
thawing the ground and creating a deeper active layer than many of the surrounding areas (Burn 2002). This, in combination with the irrigation caused by flooding, allows the vegetation to flourish (Burn 2002), creating attractive breeding and feeding habitat for shorebirds (Canadian Wildlife Service 2005).

Dry upland habitats occur throughout the study area. Upland habitats are typically patterned with small tussocks vegetated with Carex, Salix, Ericaceae, and other herbaceous plants and patches of shrubs up to $3 \mathrm{~m}$ in height. Also associated with upland habitats are valleys with small wetland patches featuring a combination of low- and high- centered polygons.

\section{Whimbrel Field Surveys}

In 2006, our field studies began on 7 June, after water levels subsided from seasonal flooding of the outer Delta, and continued until 18 July, after all Whimbrel nests had hatched. In 2007, surveys began on 7 June and continued until 21 July. We established our camps in coordination with ongoing shorebird research by CWS as part of the arctic survey component of the Program for Regional and International Shorebird Monitoring (PRISM). Camp locations were selected based on previous identification of sites as good shorebird breeding habitat by Gratto-Trevor (1996; unpublished report) and a preliminary visit in July 2005 that confirmed the continued presence of breeding Whimbrel. In 2006, camp was established on Taglu Island $\left(69^{\circ} 22^{\prime} 4^{\prime \prime} \mathrm{N}, 134^{\circ} 57^{\prime} 17^{\prime \prime} \mathrm{W}\right)$ and in 2007 on Fish Island $\left(69^{\circ} 22^{\prime} 21^{\prime \prime} \mathrm{N}, 134^{\circ} 53^{\prime} 38^{\prime \prime} \mathrm{W}\right)$. We used a small zodiac to travel between Taglu and Fish islands and throughout KIBS.

We intensively surveyed ( $>4 \mathrm{hrs}$ per site per day) Taglu and Fish islands for Whimbrel nests in both years of the study. In addition, the PRISM survey crew conducted detailed shorebird surveys on five 12-ha plots in lowland areas of Taglu Island in 2006 and five plots on Fish Island in 2007. In 2007, four of five Taglu Island plots from 2006 were also resurveyed. Preliminary surveys of these areas were conducted to determine shorebird presence before selection. These plots were surveyed daily, and nests and nesting activities of all birds, including Whimbrel, were recorded.

Whimbrel are readily detected when present in an area, and we believe our detectability rate was effectively $100 \%$ for nesting pairs. They are aggressive and act defensively when a human intruder is within several hundred meters of a nest. When plots with nesting Whimbrel were surveyed on multiple occasions, such as during the intensive PRISM surveys, Whimbrel were invariably detected on every visit. Aggressive displays, scolding trill calls, and flushing are all typical of Whimbrel nesting behavior (Skeel and Mallory 1996). We were also able to locate most nests through behavioral observations. When a pair was observed exhibiting defensive behavior, we searched all raised areas (raised mounds and ridges) in the vicinity of the pair, until the nest was located. The density of Whimbrel nesting on Taglu and Fish islands sometimes resulted in overlapping home ranges and caused some difficulty in determining which area a pair was defending. When it appeared that two pairs of Whimbrel were acting aggressively toward surveyors, surveyors would split up and lure the pairs apart to identify the individual territories. Once a surveyor was in their immediate territory, the pair would focus only on that surveyor, making it easier to locate the nest. We used a Global Positioning System (GPS) to record nest location and described the habitat at each nest. If a nest could not be located, the site was revisited until surveyors could be confident that the Whimbrel observed was either a failed nester or a non-breeder.

To evaluate the satellite classification and to locate additional Whimbrel habitat, we surveyed an additional 55 patches of habitat throughout KIBS, ranging in size from $20-100$ ha in various locations outside of the study sites on Taglu and Fish islands for evidence of breeding Whimbrel. These habitat patches were selected by visual interpretation of satellite imagery and aerial photos for the area to represent each of the habitat types identified through our remote-sensing classification (see below). We made a particular effort to survey all areas that appeared to be wet sedge LCP habitat similar to that found on Fish and Taglu islands. To ascertain Whimbrel presence or absence, we walked extensively throughout the habitat patch looking for Whimbrel; as noted above, if Whimbrel were present we are confident that we would have found them due to their vocal and aggressive behavior toward intruders. When a Whimbrel pair was located, we searched intensively until the nest was located. At each location, we described the habitat based on its primary vegetation type, relief (LCPs, high-centered polygons, tussock meadows, graminoid meadows), and soil moisture and land aspect. Visual 
estimates were made of the percentage of ground cover (graminoids, low shrubs, tall shrubs, mosses and lichens, bare ground, water). We recorded the coordinates for the location with a GPS and took digital photographs of each site. Some of this ground-truthing information was used as "training data" for the classification, and the rest for assessing the accuracy of the remote-sensing classification.

\section{Habitat Classification Using Remote-Sensing Data}

Geo-referenced IKONOS 2 multispectral and panchromatic imagery (Table 1) of KIBS and Fish Island was acquired by the CWS from Space Imaging Inc. The imagery consisted of three scenes, each with an 11.3-km swath width (GeoEye 2006). The first scene was collected 22 June 2002; the second and third scenes were collected on 8 August 2002. We classified each scene individually because of spectral differences between the images. A small amount of cloud contamination was present in the imagery, which we masked and excluded from our analysis along with gravel pads and other manmade habitat.

Using Focus for PCI Geomatica ${ }^{\circledR}$ 10.0, we conducted supervised classifications using the red, green, blue, and near-infrared spectral bands for each of the three IKONOS scenes to produce a thematic map of the study area (Lillesand et al. 2004). We used ground-truthing data that were collected in 2006 and 2007 to identify representative areas of land cover to train the supervised classification. The supervised classification analyzed the spectral characteristics of these areas and identified pixels of like spectral qualities, creating a thematic map representing various landcover types.

We selected six habitat classes, excluding water, to be represented by our classification: wet sedge lowland habitats, saturated habitats, dry upland tundra habitats, tall willow stands, dense shrub lowland habitats, and dry graminoid lowland habitats. We used the maximum likelihood classifier algorithm to determine spectrally similar areas within the imagery (Natural Resources Canada (NRCAN) 2007). To remove unwanted fine-scale noise from the classified images, we used a 5 x 5 pixel FMO - Mode Filter (filter mode). The filter mode is a smoothing algorithm that computes the most frequently occurring habitat value within the $5 \times 5$ pixel filter window surrounding each pixel, to classify isolated pixels to match their surrounding pixels. Our final classification resulted in three thematic maps (one for each scene) containing a mosaic of pixels, each belonging to one of the landcover classes of interest.

To determine the area of water in the imagery, we conducted a separate supervised classification of the IKONOS imagery using the red, green, and nearinfrared multispectral bands. Several categories were created due to the large differences in spectral reflectance of the various water bodies. Thematic maps representing water were created for each of the three scenes and integrated into the original classifications.

We subsequently performed an accuracy assessment of the final supervised classifications by sampling 100 random pixels $(4 \mathrm{~m} \mathrm{x} 4 \mathrm{~m})$ of nonwater distributed throughout each of the three scenes. We compared each random pixel from the classified imagery with our knowledge of habitat (based on a combination of ground-truthing data and visual interpretation of the original, high-resolution false-color satellite image) to determine the percentage of the image that was correctly classified. We stratified the samples to land-cover class percentages to provide a proportional representation of the image occupied by each landcover class (PCI Geomatics 2005).

We converted the classified images into raster thematic maps using ArcMap $®$. We vectorized the raster maps to produce shapefiles identifying each habitat class (PCI Geomatics 2005) and calculated the total area classified for each habitat using Hawth's Tools (Beyer 2008).

To supplement the spectral analysis, we used ArcMap to combine the multispectral bands with the higher resolution $(1 \mathrm{~m})$ panchromatic band to create a pan-sharpened multispectral image (Lillesand et al. 2004). The resulting pan-sharpened multispectral image was visually examined to identify areas of non-shrubby lowland habitat from the classified images that exhibited wet-sedge LCP patterns. We then digitized these areas in ArcMap to create polygon shapefiles and integrated them with the map produced from the spectral analysis. 
Table 1. Spectral ranges and resolutions of IKONOS bands used in the supervised classification.

\begin{tabular}{lccc}
\hline \hline Band & Spectral Range $(\mathrm{nm})$ & Spectral Area & Ground Resolution $(\mathrm{m})$ \\
\hline 1 & $445-516$ & Blue & 4 \\
2 & $506-595$ & Green & 4 \\
3 & $632-698$ & Red & 4 \\
4 & $757-853$ & Near-infrared & 4 \\
Pan & $526-929$ & Panchromatic & 1 \\
\hline
\end{tabular}

\section{Scenario Analysis of Whimbrel Habitat}

We used ArcMap 9.2 and our final habitat classification maps to run scenario analyses to estimate the potential impact of the MGP on Whimbrel breeding habitat. Using ArcMap Model Builder®, we developed a visual modeling framework that automated a combination of geoprocessing tasks to develop three scenario analyses assuming effectively complete loss of habitat within $20-, 50-$, and 250-m buffers on all sides of the proposed pipeline trench and Taglu facility. The 20$\mathrm{m}$ buffer was selected based on the 40-m right-ofway for the construction of the proposed pipeline trench and represents the minimum amount of habitat loss or alteration. The 50-m and 250-m buffers were chosen to evaluate the impact of various levels of disturbance effects. The pipeline proposal suggested that major disturbance effects could extend up to $250 \mathrm{~m}$ away from pipeline and facility construction and operations (AMEC Americas Limited, unpublished report).

Our observations of Whimbrel behavior toward human intruders in the 2006 and 2007 field seasons roughly provided an estimate of approximate territory size (Pirie 2008). We used the average territory size to estimate the maximum number of breeding Whimbrel pairs each area of good habitat could support (based on territory size and available habitat) and the maximum number of breeding pairs that could potentially exist in the habitat remaining for each scenario. The maximum number of pairs was also determined based on territory size if we assumed that in 2006 and 2007 the lowland habitat was saturated.

We used a different approach to estimate the potential impact of subsidence-induced flooding on Whimbrel nesting habitat on Taglu and Fish islands. We used information on the locations and heights of Whimbrel nests and five randomly selected ridges or mounds within each territory that did not have nests ("non-nests") from Pirie (2008) to determine the proportion of potential nest sites that might be lost due to subsidence. The proponent for the MGP presented a model that predicted a maximum subsidence of $0.38 \mathrm{~m}$ near the center of the projected subsidence bowl resulting from $30 \mathrm{yrs}$ of natural gas extraction on Taglu Island (Imperial Oil Resources Ventures Limited 2007). Environment Canada created a grid that indicated contours of the projected subsidence bowl by creating a Triangular Irregular Network (TIN) from a series of subsidence points generated by the proponent. We plotted nest and non-nest locations over top of the grid and calculated the estimated subsidence value at each site using spatial analyst (extract to points) in ArcMap to determine whether the nest or a potential nest would remain above water under the 30-yr subsidence predictions. 


\section{RESULTS}

\section{Identification of Whimbrel Breeding Habitat through Ground Surveys}

Whimbrel were found nesting, foraging and chickrearing in wet-sedge LCP habitat on Taglu and Fish islands. In each of 2006 and 2007, we found 14 pairs of Whimbrels in these areas. All 28 nests that we found were located on low ridges or raised mounds associated with the LCP structure. Whimbrel nest sites were vegetated with a combination of dwarf and low shrubs (Salix, Betula, and Alnus spp.), hydrophilic graminoids (Carex and Eriophorum spp.), mosses and herbs (Equisetum sp., Fabaceae, Dryas sp., Scrophulariaceae, and others). Radiotracking studies showed that Whimbrel remained in the same area for foraging and chick-rearing activities (Pirie 2008).

Ground surveys of other lowland habitat patches, of varying degrees of structural complexity $(n=43$; Fig. 5), selected through visual interpretation of the IKONOS imagery, did not find breeding Whimbrel activities. This includes four areas that appeared to be wet-sedge LCP habitat similar to that of Taglu and Fish islands but actually were too dry, had limited structural complexity, or had high densities of shrubs.

Whimbrel were also observed nesting in an estimated $50 \%$ of the upland habitat that we surveyed, but at much lower densities. We surveyed approximately 12 patches of upland tundra habitat (6000 ha or about $75 \%$ of all upland habitat in the study area) in the outer Delta for Whimbrel presence. We found one Whimbrel nest in a dry upland habitat that was next to wetland valleys containing a network of both LCP and high-centered polygon structures, one of three upland patches that were surveyed in June during the peak of the breeding season. No signs of Whimbrel were observed in the two other patches surveyed at that time. Two to three pairs of Whimbrel were observed exhibiting parental behavior in three of nine upland patches we visited in July, late in the breeding season, but no nests were found.

\section{Evaluation of Land-Cover Classification from Remote Sensing}

Our final classification based on spectral classification techniques (Fig. 6) consisted of four land-cover classes described in Table 2: nonshrubby lowland habitats, saturated habitats, dense shrub lowland habitats, and dry upland tundra habitats. Two of our initial six habitat classes had poor signature separability from the other classes, so we reduced the final classification to four landcover classes by combining areas with dense shrubs and stands of tall trees $(>3 \mathrm{~m})$ found in riparian zones into one category and by combining wet-sedge and dry graminoid lowland habitats into another. In addition, a fifth class was created to represent "Not Classified" areas, areas of the imagery that could not be assigned to one of the four major land-cover classes. All of the final land-cover classes had distinctly different spectral signatures with the exception of dry upland tundra habitats and dense shrub lowland habitats in scenes 2 and 3 (Table 3 ).

The classification of the imagery was unable to identify $31 \%$ of the terrestrial landscape. Visual examination of the images suggested that most unclassified areas were not areas of importance for Whimbrel breeding. Most were edges and transition habitats, particularly between water and terrestrial areas. Some areas were small patches of upland habitats and were added to the areas considered upland potentially suitable for Whimbrel. Some small inland lakes and ponds in the imagery were unclassified due to the wide spectral variation in water throughout the imagery. Figure 7 shows how each habitat class appears in the IKONOS imagery, together with a ground photograph of the actual habitat.

Analysis of classification accuracy based on ground-truthing data or visual assessment of the pan-sharpened image indicated overall accuracies for the three scenes of $77 \%, 74 \%$, and $85 \%$, respectively (Table 4). Non-shrubby lowland classification resulted in the lowest errors of omission and commission overall, with nonshrubby lowlands being correctly classified $80 \%$ $96 \%$ of the time (Table 4). Scene 1 had the highest errors of omission for this land-cover type. The assignment of incorrect habitat types to the lowland habitat class was infrequent and usually resulted in the inclusion of shrubby habitat. Classification of saturated and shrubby habitats produced higher errors of omission, with several pixels being "Not Classified." Errors of commission were low for saturated habitats but were higher for shrubby habitat due to the frequent incorrect assignment of upland habitat to this class. The upland habitat class in Scenes 1 and 3 had low error levels, but scene 2 
Fig. 5. Locations of surveyed ground-truth plots in KIBS and on Fish Island in the outer Mackenzie Delta, Northwest Territories. Non-shrubby lowland sites (yellow stars); dry upland tundra sites (orange circles); dense shrub lowland sites (green diamonds); low-centered polygon habitat (blue asterisks); areas of observed breeding Whimbrel activities (pink crosses). Survey sites may have extended up to several hundred meters from the marked locations.

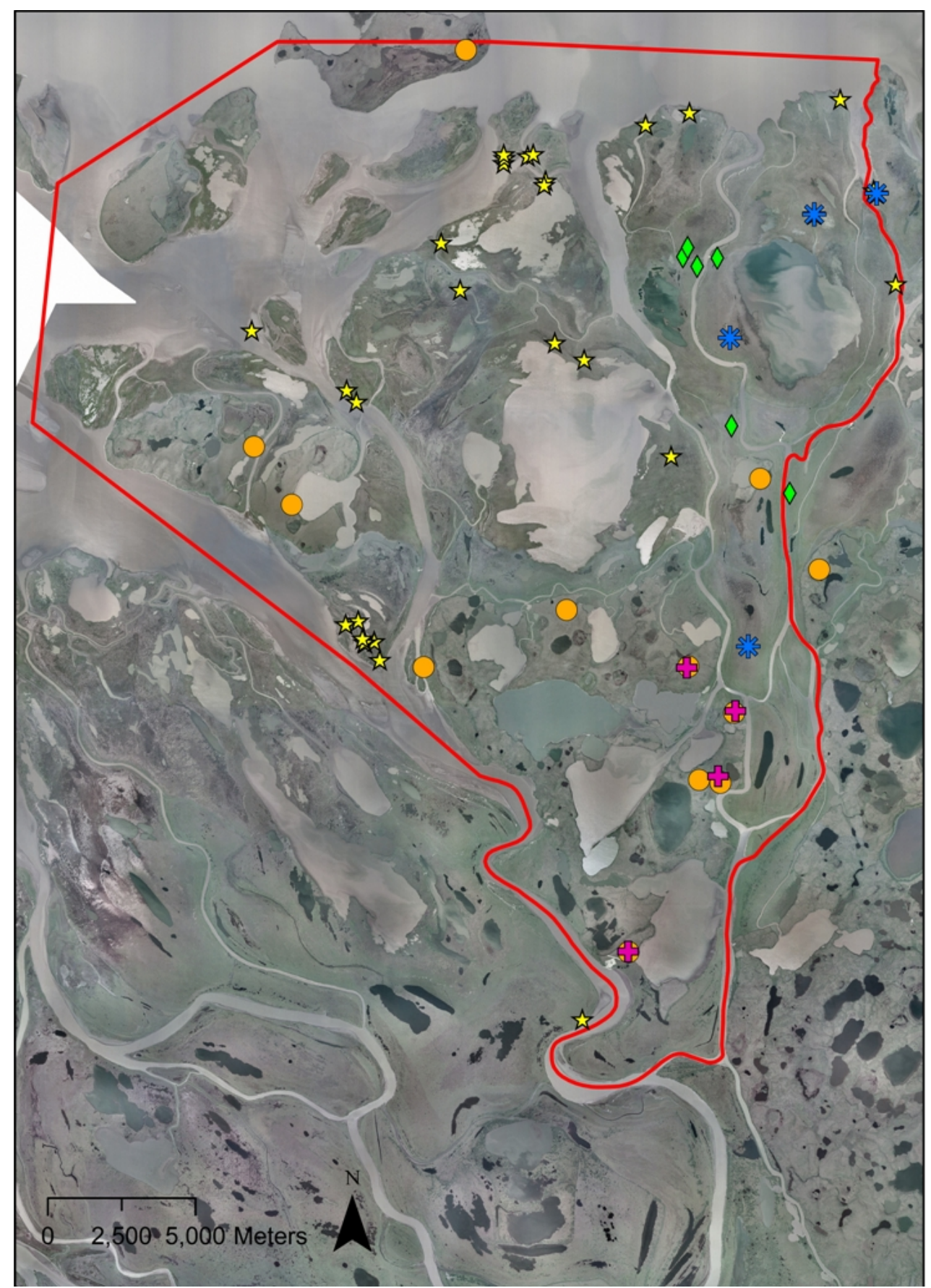


Fig. 6. Land-cover map of the Kendall Island Bird Sanctuary and Fish Island in the outer Mackenzie Delta, Northwest Territories showing four land-cover classes derived from a supervised classification of Ikonos imagery, as well as areas that were unidentified in the classification, water bodies, and areas that were masked out of the imagery before classification. In addition, areas of wet-sedge low-centered polygon habitat were distinguished from within the non-shrubby lowland habitat by visual pattern analysis of the imagery.

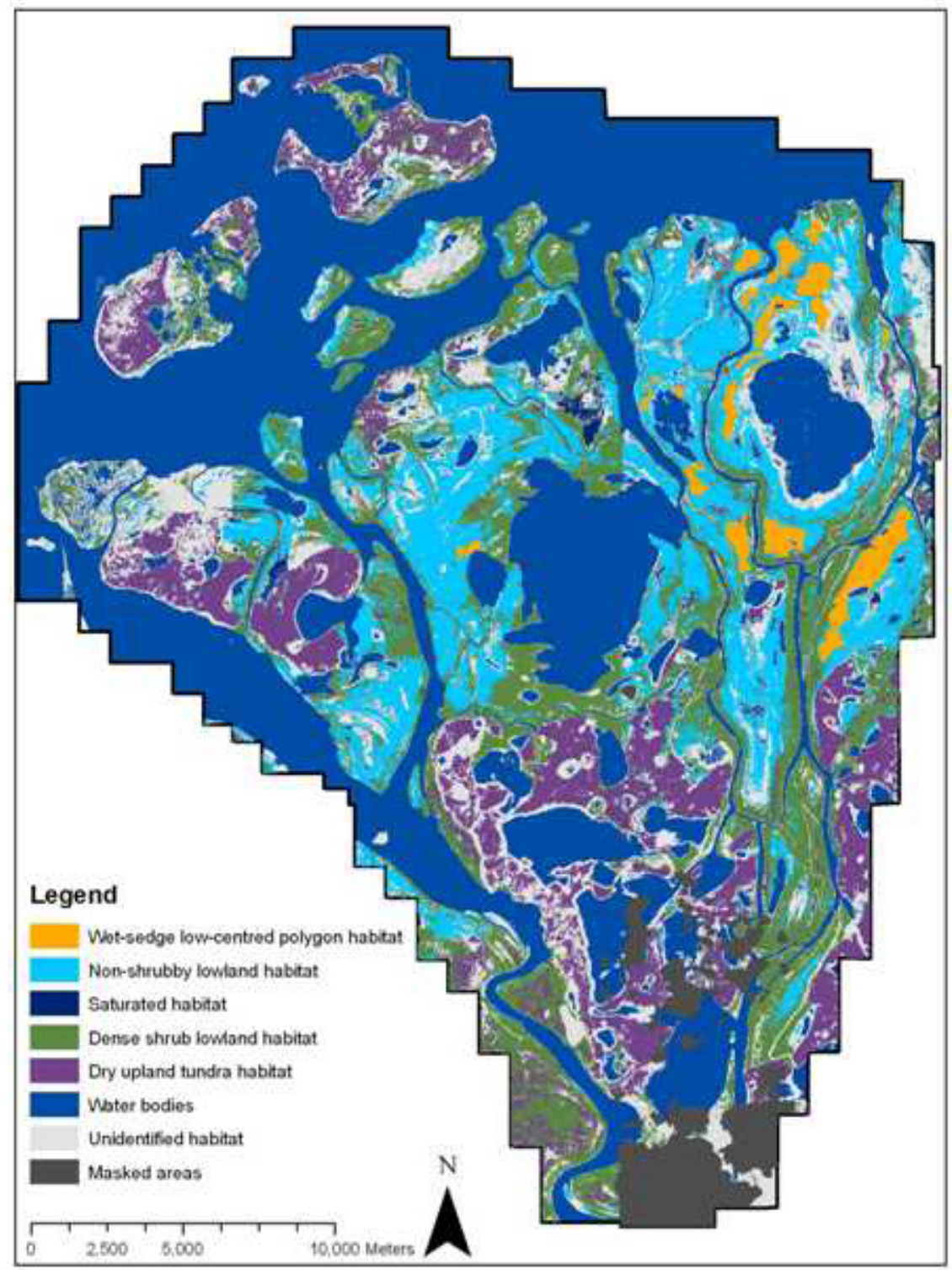


Table 2. Description of each land-cover class, the percentage of terrestrial habitat it encompasses, and the area estimates of land-cover classes from the supervised classification of the Kendall Island Bird Sanctuary and Fish Island in the outer Mackenzie Delta, Northwest Territories.

\begin{tabular}{|c|c|c|c|}
\hline Class & Description & $\begin{array}{l}\text { Percentage } \\
\text { terrestrial habitat }\end{array}$ & $\begin{array}{c}\text { Total area in } \\
\text { ha }\end{array}$ \\
\hline $\begin{array}{l}\text { Non-shrubby lowland } \\
\text { habitat }\end{array}$ & $\begin{array}{l}\text { Areas of lowland meadows with vegetative covers of } \\
\text { LCP habitat, flat graminoid meadows, or areas void of } \\
\text { vegetation. Levels of moisture range from dry to } \\
\text { moderately wet. }\end{array}$ & 25 & 11752 \\
\hline Saturated habitat & $\begin{array}{l}\text { Areas characterized by deep }(>15 \mathrm{~cm}) \text { standing water } \\
\text { that often contains LCP or high-centered polygon } \\
\text { structures. In areas of LCP habitat, vegetation } \\
\text { predominantly consists of hydrophilic sedges with little } \\
\text { or no herbaceous or shrubby vegetation. High-centered } \\
\text { polygon habitats are typically covered with heaths and } \\
\text { other herbaceous plants. }\end{array}$ & 0.7 & 308 \\
\hline $\begin{array}{l}\text { Dense shrub lowland } \\
\text { habitat }\end{array}$ & $\begin{array}{l}\text { Areas where the predominant vegetation cover was } \\
\text { composed of dense shrubs or tall willow stands with no } \\
\text { open areas present. Habitat may be wet or dry. }\end{array}$ & 26 & 12401 \\
\hline Dry upland tundra habitat & $\begin{array}{l}\text { Areas dominated by tussocks. Widespread herbaceous } \\
\text { plants and patches of low shrubs }(<1 \mathrm{~m} \text { tall }) \text { are } \\
\text { interspersed throughout. }\end{array}$ & 17 & 8140 \\
\hline Not Classified (Null Class) & $\begin{array}{l}\text { Any area that could not be indentified as one of the } \\
\text { above classes. }\end{array}$ & 31 & 14565 \\
\hline Water bodies & Ponds, rivers, lakes, ocean & NA & 38337 \\
\hline
\end{tabular}

had high errors of commission $(48 \%)$ resulting from incorrect assignment of upland habitat pixels to shrubby habitats (Table 4).

The classification of the image, based on spectral characteristics, was unable to distinguish wet-sedge LCP from other non-shrubby lowland habitat, but we were able to distinguish this habitat by visual examination of patterns on the pan-sharpened image (Fig. 8a). In this way, we identified 1168 ha of wetsedge LCP habitat within the study area (including 470 ha on Taglu and Fish islands), representing approximately $10 \%$ of the non-shrubby lowland land-cover type identified from the IKONOS imagery. This habitat class was manually digitized onto the original classification map (Fig. 6).

Surveys of wet-sedge LCP habitat outside Taglu and Fish islands (698 ha) failed to find any nesting Whimbrels. However, that habitat differed from known Whimbrel nesting habitat in being either drier (lacking standing water in the polygon centers), having very poor structural complexity (limited patterned ground), or in having high shrub densities on the polygon ridges.

\section{Modeling the Potential Impact of the Mackenzie Gas Project}

Our scenario analyses of the impacts of disturbance associated with construction and operation of the MGP suggest a loss of $7.6 \%$ to $28.9 \%$ of the available habitat for breeding Whimbrel, depending on the assumed radius of impact (Table 5). To estimate the impact of this loss on Whimbrel populations requires an estimate of Whimbrel territory size. If we assume the existing habitat is saturated with 14 pairs, representing an average habitat requirement of 33 ha per pair, then the 
Table 3. Signature separability between land-cover classes used in the supervised classification. Values are calculated as the statistical difference between parts of spectral signatures using Bhattacharrya Distance methods. A value of 0 indicates a complete overlap in the spectral signature between the two classes and a value of 2 indicates complete separation. Habitat type numbers across the top match those on the side.

\begin{tabular}{|c|c|c|c|c|c|c|c|c|c|}
\hline \multirow[b]{2}{*}{ Class } & \multicolumn{3}{|c|}{ Scene 1 Separability } & \multicolumn{3}{|c|}{ Scene 2 Separability } & \multicolumn{3}{|c|}{ Scene 3 Separability } \\
\hline & 1 & 2 & 3 & 1 & 2 & 3 & 1 & 2 & 3 \\
\hline \multicolumn{10}{|l|}{$\begin{array}{l}\text { (1) Non-shrubby lowland } \\
\text { habitat }\end{array}$} \\
\hline (2) Saturated habitat & 1.99 & & & 1.99 & & & 1.99 & & \\
\hline (3) Dense shrub lowland habitat & 1.99 & 1.99 & & 1.79 & 2.00 & & 1.56 & 2.00 & \\
\hline (4) Dry upland tundra habitat & 1.99 & 2.00 & 1.79 & 1.99 & 2.00 & 1.11 & 1.95 & 2.00 & 1.29 \\
\hline
\end{tabular}

maximum number of pairs that would be supported is reduced from 14 to 10 pairs under the $250-\mathrm{m}$ radius of impact scenario. However, our observations suggest that Whimbrel typically become aggressive toward human intruders at about $250 \mathrm{~m}$ from the nest edge in wet-sedge LCP habitat, suggesting an approximate territory size of 20 ha in this area. If this is the case, the maximum carrying capacity would be reduced from 23 to 16 pairs, but even the lowest of these numbers is higher than the current number of breeding pairs.

However, our estimates of the impacts of subsidence suggest that most suitable nesting habitat on Taglu and Fish islands could become inundated. If the predicted maximum subsidence were to occur as a result of gas extraction at the proposed Taglu processing facility, 18 of 28 observed Whimbrel nest sites (64\%) would become completely submersed and would no longer be suitable nesting habitat. Random non-nest sites were on average lower in elevation above standing water $(0.13 \mathrm{~m}$; $\mathrm{SE}=0.006)$ than Whimbrel nests $(0.18 \mathrm{~m} ; \mathrm{SE}=$ $0.01)$. Out of 140 random non-nest sites, $131(78 \%)$ would potentially be flooded and lost as potential Whimbrel nesting habitat. Most of the remaining sites would be very low to the water and might no longer be suitable for Whimbrel.

\section{DISCUSSION}

\section{Whimbrel Breeding Habitat}

Our study confirms the presence of small breeding communities of Whimbrel in wet-sedge LCP habitat on Taglu and Fish islands and to a lesser extent in upland habitat with adjacent wetland valleys in the outer Mackenzie Delta. Whimbrel have previously been observed in both wet-sedge LCP habitat and upland tundra habitats in the Mackenzie Delta (Gratto-Trevor 1996, Ashenhurst 2004; Dickson et al., unpublished report; C. L. Gratto-Trevor, unpublished report). Dickson et al. (unpublished report) found that shorebirds in the outer Mackenzie Delta appear to have a strong preference for welldeveloped LCP habitat. We found about 14 pairs in 470 ha of lowland LCP habitat, compared with only three to four pairs in about 6000 ha of upland habitat. Although uplands hosted fewer Whimbrel than lowland habitats within our study area, upland habitats are more extensive elsewhere in the Mackenzie Delta and so, even at low densities, could support significant numbers of Whimbrel.

Structural complexity, availability of raised ground, low shrub densities, and moderate levels of moisture all appear to be important components of preferred Whimbrel breeding habitat in the outer Delta. No Whimbrel were observed in areas of saturated habitat that are structurally similar to wet-sedge LCP habitat. Presumably these habitats were not 
Fig. 7. Clips of IKONOS imagery representing the different habitat types, with corresponding photographs of the representative habitat. Yellow crosses indicate the specific location represented by the photograph. (a) Non-shrubby lowland habitat; (b) saturated habitat; (c) dense shrub lowland habitat; (d) dry upland tundra habitat; (e) wet-sedge low-centered polygon habitat.
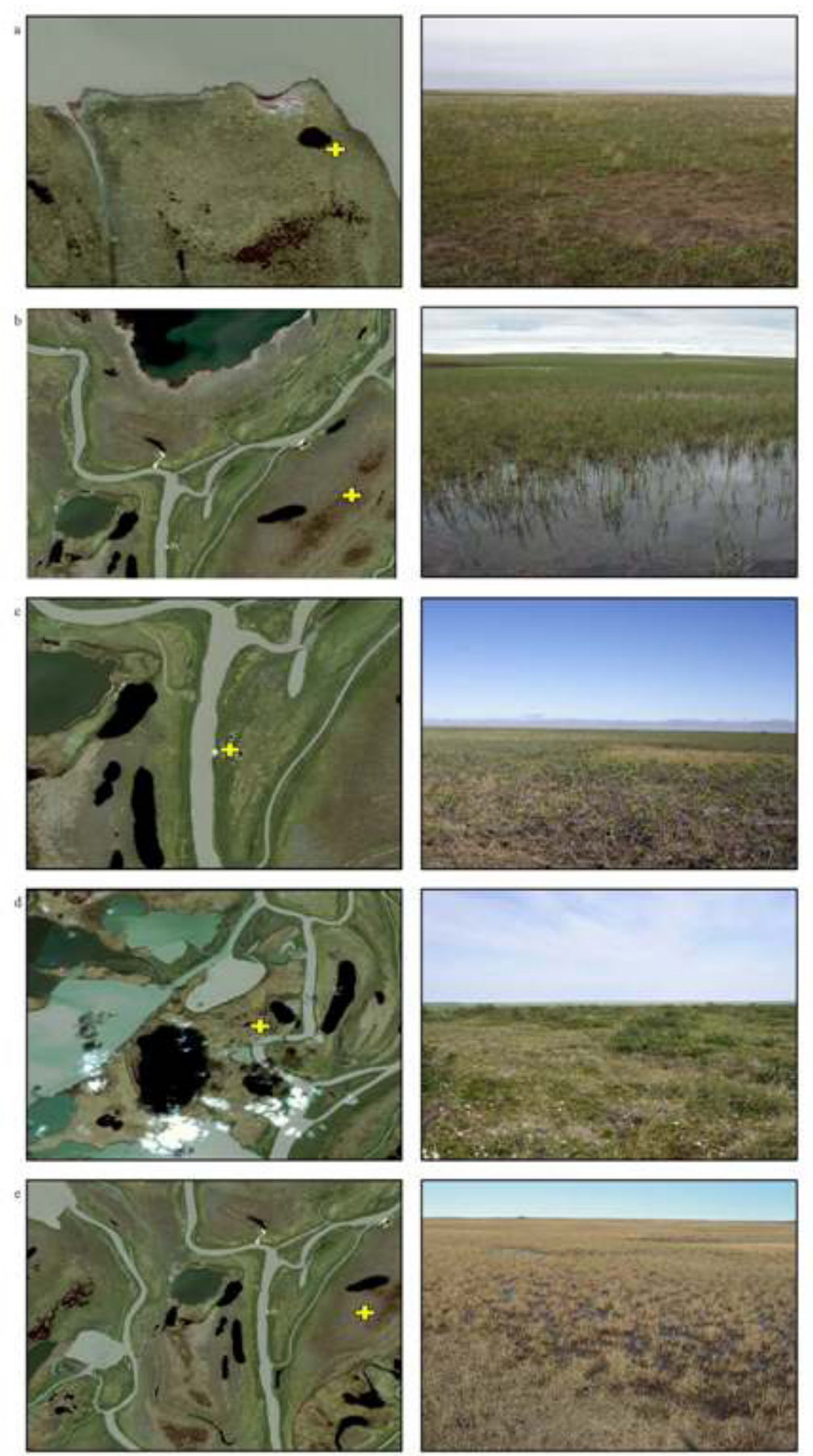
Table 4. Error matrix resulting from accuracy assessment of the supervised classification for the three scenes representing the Kendall Island Bird Sanctuary and Fish Island in the outer Mackenzie Delta, Northwest Territories. Values represent the number of pixels classified as a particular habitat type in relation to their actual habitat type, out of 100 in each scene. Incorrect values reading down represent errors of omission (pixels incorrectly excluded from a habitat class), whereas incorrect values reading across represent errors of commission (pixels incorrectly included in a habitat class). A total of 100 pixels were sampled from each scene, with an estimated overall accuracy of $77 \%, 74 \%$, and $85 \%$ in scenes 1,2 , and 3 , respectively.

Actual Habitat Type

$\begin{array}{lll}\text { Scene } 1 & \text { Scene } 2 & \text { Scene } 3\end{array}$

\begin{tabular}{l}
$\begin{array}{l}\text { Actual Habitat } \\
\text { Type: }\end{array}$ \\
\hline
\end{tabular}

Classified Habitat

Type:

(1) Non- shrubby lowland habitat

$\begin{array}{llll}20 & 0 & 0 & 0\end{array}$

\begin{abstract}
$0 \%$
\end{abstract}

$\begin{array}{llll}26 & 0 & 2 & 0\end{array}$

$7 \%$

25

$\begin{array}{lll}0 & 2 & 0\end{array}$

$7 \%$

(2) Saturated

habitat

$1 \quad 14 \quad 0 \quad 0$

$7 \%$

$\begin{array}{llll}0 & 12 & 0 & 0\end{array}$

$0 \%$

$\begin{array}{llll}0 & 14 & 0 & 0\end{array}$

$0 \%$

(3) Dense shrub lowland habitat

$\begin{array}{lllll}0 & 1 & 19 & 1 & 10 \%\end{array}$

$\begin{array}{llll}2 & 0 & 24 & 3\end{array}$

$17 \%$

$\begin{array}{llll}0 & 0 & 21 & 2\end{array}$

$9 \%$

(4) Dry upland
tundra habitat

$\begin{array}{llll}0 & 0 & 1 & 24\end{array}$

$4 \%$

$\begin{array}{llll}0 & 0 & 11 & 12\end{array}$

$48 \%$

$\begin{array}{llll}0 & 0 & 3 & 25\end{array}$

$11 \%$

(5) Not classified

$\begin{array}{lllll}4 & 5 & 8 & 2 & \text { N/A }\end{array}$

$\begin{array}{llll}1 & 6 & 1 & 0\end{array}$

N/A

$\begin{array}{llll}1 & 6 & 1 & 0\end{array}$

N/A

\% Error Omission

$\begin{array}{llll}20 & 30 & 32 & 11\end{array}$

$\begin{array}{llll}10 & 33 & 37 & 20\end{array}$

$\begin{array}{llll}4 & 30 & 22 & 7\end{array}$

suitable for Whimbrel both because of the presence of deep standing water, which would make it difficult for Whimbrel broods to travel, and the lack of suitable dry ridges or mounds for nest sites. Whimbrel would likely benefit from nesting in areas with numerous choices of nesting sites as a predator avoidance strategy - both avian and mammalian predators were common in the area. The absence of breeding Whimbrel in other areas identified from remote-sensing imagery as wet-sedge LCP habitat may be attributed to higher densities of shrubs on polygon ridges and raised mounds, which we observed in these areas. Areas with dense shrubs may be avoided by breeding Whimbrel due to restricted vision of approaching predators to nesting birds. Götmark et al. (1995) suggested that it may be beneficial for adults to have good visibility at the nest to reduce the risk of predation during incubation.

\section{Evaluation of Use of Remote-Sensing Data to Map Whimbrel Habitat}

We found that supervised classification methods using high-resolution IKONOS imagery were moderately successful at differentiating land cover into four broad habitat categories in the outer Mackenzie Delta. We initially attempted to differentiate six land-cover types to allow for mapping of a greater diversity of habitats, but the classification accuracy was unacceptably low. Classification accuracy generally improves with a decrease in the number of land-cover classes (Rees 
Fig. 8. A comparison of low-centered polygon structure and habitat as seen in (a) pan-sharpened IKONOS and (b) aerial photographs.

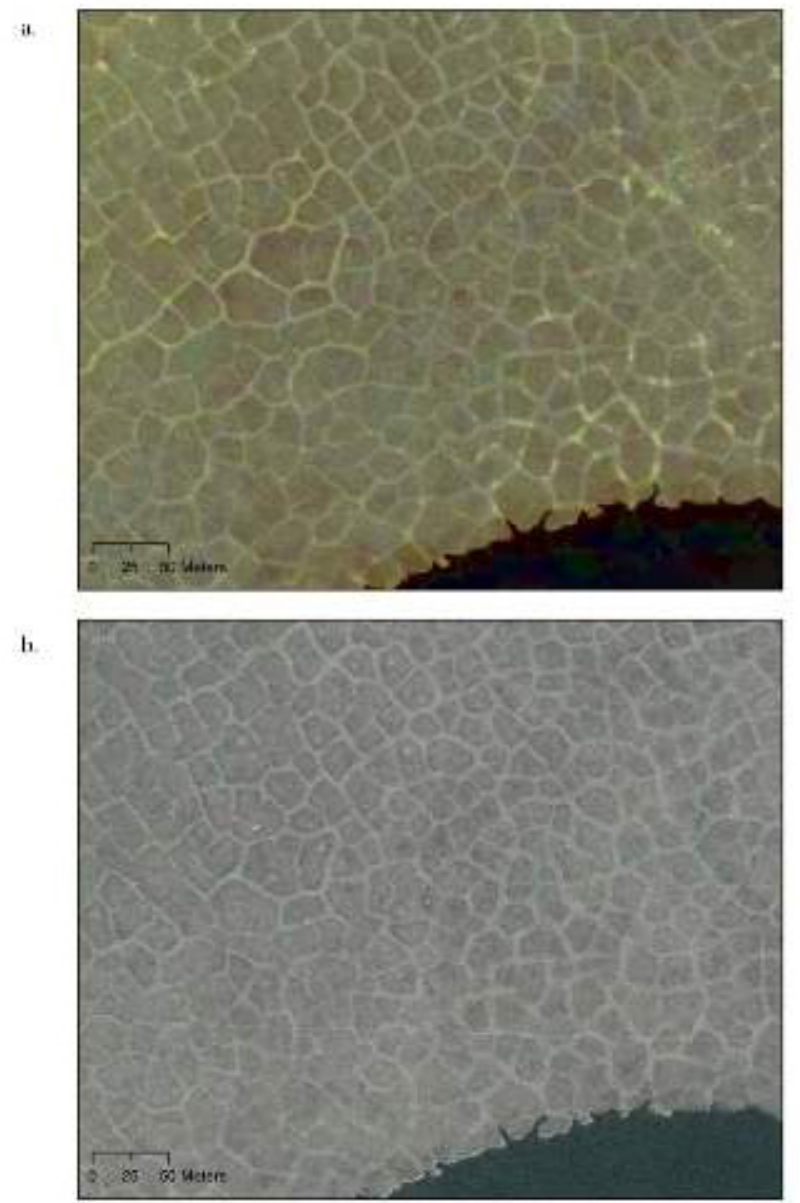

2001). Overall, the spectral signatures of the final four classes showed nearly complete separation, although separation of upland habitat and shrubby habitat in scenes 2 and 3 was less complete. This may be because these scenes were collected in August after vegetation had flourished, which could cause similar reflectance values between upland habitat with high levels of herbaceous vegetation and shrubby habitat dominated by willows.

Overall, the supervised classification procedure was fairly accurate at identifying non-shrubby lowlands, the most important class for identifying potential lowland Whimbrel breeding habitat, but was not able to distinguish areas of LCP from other lowland areas. It was necessary to combine the supervised classification with visual interpretation of the image, followed by manual digitizing of boundaries to map these habitat types. Potentially, we could have started directly with visual interpretation, but the supervised classification was useful for narrowing down the area requiring visual interpretation. A number of software packages such as eCognition $\AA$ (Definiens 2009) have been developed to allow classification of satellite imagery through pattern recognition, in a similar fashion to our visual analysis of the image. We did not attempt to use any of these packages because it was more efficient for us, given the limited land area that was identified as lowland non-shrubby habitat, 
Table 5. Results for three scenarios potentially resulting from the construction of a natural gas-processing facility and pipeline in breeding Whimbrel habitat on Taglu and Fish Island in the outer Mackenzie Delta, Northwest Territories.

\begin{tabular}{|c|c|c|c|c|}
\hline & No buffer & 20-m buffer & 50-m buffer & 250-m buffer \\
\hline Habitat lost (ha) & 0 & 35.5 & 54.3 & 94.7 \\
\hline Habitat remaining (ha) & 470 & 434.5 & 415.7 & 334.0 \\
\hline Percentage habitat lost & 0 & 8 & 12 & 29 \\
\hline Max. Whimbrel Pairs (20 ha/territory) ${ }^{1}$ & 23 & 21 & 20 & 16 \\
\hline Max. Whimbrel Pairs (33 ha/territory) ${ }^{2}$ & 14 & 13 & 12 & 10 \\
\hline
\end{tabular}

${ }^{1}$ Maximum number of possible breeding Whimbrel pairs the area of habitat remaining could support based on an average territory size of 20 ha.

2 Maximum number of possible breeding Whimbrel pairs the area of habitat remaining could support based on a territory size of 33 ha.

to carry out a manual/visual classification of that area. Given that the LCP has a fairly regular geometric pattern (Fig. 8a, b), it may be possible to train some of these software packages to recognize it. However, there would likely still be some errors, and an evaluation of the efficiency of such an approach was beyond the scope of our study.

Even after visual classification of the LCP habitats using remote-sensing data, it was necessary to visit each area on the ground to evaluate its suitability for Whimbrel. All of the LCP areas identified outside of Taglu and Fish islands proved unsuitable because they were too dry, had limited structural complexity, or had dense shrubs on the ridges. However, the satellite imagery was critical in allowing us to identify the appropriate areas for ground visitation.

Edges and transition habitats, as well as a large portion of the dry upland tundra, were poorly classified by the spectral analysis process. This may be due in part to the varying slopes throughout the habitat, particularly around the periphery and in areas that slope into small wetland valleys. Slopes can result in shadows that change the spectral characteristics of the habitat (Gratto-Trevor 1996). Although this affected the accuracy of the estimated area of this land-cover class from the automated process, visual examination of the unclassified areas in the false-color image fairly readily allowed identification of upland habitat. Visually identified upland areas were included when selecting areas to search for Whimbrel.

Although spectral analysis of IKONOS imagery was only sufficient to identify broad habitat classes, the pan-sharpened images $(1 \mathrm{~m} \times 1 \mathrm{~m})$ approached the resolution of aerial photographs, allowing us to visually identify many of the habitat features. Color aerial photographs (1:30 000 scale) are available for parts of the study area and provide even finer resolution $(0.5 \mathrm{~m} \times 0.5 \mathrm{~m})$, facilitating recognition of features such as LCPs and even some raised mounds (Fig. 8b). However, these photographs may be less suitable for automated classification, which, although imprecise, was valuable for narrowing the areas to be examined intensely visually. Thus, it was probably still more efficient to work with the IKONOS imagery.

The value of our approaches for mapping much larger areas of the Arctic remains untested. Our classification had to be run separately for each of the three scenes due to differences in timing of when they were taken, and hence differences in spectral 
signatures. As such, to map large areas of the Arctic, it would be necessary to have at least some known reference habitats on each scene to aid with the classification. Although this would be most accurate with ground data, we found that with the highresolution imagery it was often possible to recognize habitats visually through pattern recognition despite spectral variation. Thus, it may be possible to carry out initial classifications of many areas without actual ground data from each scene. Of course, eventual ground validation would be desirable, but it could be focused on areas predicted to be of greatest value for birds. Annual and seasonal variation in water levels and vegetation could also limit the usefulness of satellite imagery. Water levels in the Delta, as potentially in other lowlying areas of the Arctic, change from year to year as a result of different flooding regimes, storm surges, and annual changes in ice break-up. Areas that are suitable for shorebird nesting in one year could become unsuitable in other years (GrattoTrevor 1996). Nevertheless, it was encouraging that, despite the fact that we used images from different years from our study, and in two cases different seasons, they were quite helpful in mapping potential habitat.

Overall, the use of remote sensing to determine breeding habitat for arctic nesting shorebirds provided a supplement, rather than an alternative to the otherwise logistically difficult task of field surveys. A combination of techniques was required to identify the structurally complex habitat that Whimbrel use in the study area. Ground visits were still required to validate the suitability of these habitats for Whimbrel. Nevertheless, the remotesensing imagery was useful for greatly reducing the amount of area that had to be searched, while ensuring that all potentially suitable habitats were identified.

\section{Modeling the Impacts of Development}

Only a small portion of habitat in KIBS and Fish Island (470 ha) appears to be suitable for lowland Whimbrel breeding. Loss of any of this habitat could negatively affect Whimbrel breeding populations in the area. Our scenario models suggest that up to $20 \%$ of suitable habitat could be lost by disturbance factors alone due to the proposed development, assuming Whimbrel avoid areas within $250 \mathrm{~m}$ of any infrastructure.
The impact of this habitat loss on lowland breeding Whimbrel in the study area depends on a number of additional factors. If the habitat was not saturated with birds, then loss of $20 \%$ of habitat may result in relatively little loss of Whimbrel. Conversely, if the effects extend beyond $250 \mathrm{~m}$ (e.g., through increased predation), the actual loss could be higher.

Subsidence could have a more extensive, additional impact on Whimbrel. The potential for subsidence or decrease in land elevation, occurring as a result of the extraction of natural gas from the underground reservoir could result in low-lying areas used by breeding Whimbrel becoming inundated with water and therefore unsuitable. Subsidence models suggest a minimum of 758 ha of habitat of migratory bird habitat in KIBS would be impacted by subsidence (Environment Canada 2007). Additional subsidence may also occur as a result of the melting permafrost because of the effects of winter construction and maintenance activities (Lawson 1986, Felix and Raynolds 1989, Emers et al. 1995). Most of the raised polygon ridges and mounds were only $10-20 \mathrm{~cm}$ above water, and our analyses indicate most of them would become submersed.

Additional factors could be considered for a more comprehensive scenario analysis to predict the effects MGP might have on Whimbrel breeding habitat in the Mackenzie Delta. Construction of elevated structures could increase the number of predators by creating additional platforms for feeding, perch hunting, or nesting (Truett et al. 1994). A number of manmade structures already present in the study area (NorthwesTel Cellular Communications tower, tall pilings) serve as artificial perches or nesting sites for Rough-legged Hawks (Buteo lagopus) and Ravens (Corvus corax).

An additional challenge to modeling impacts is consideration of yearly climate fluctuations, possible long-term changes in water levels associated with climate change, the possibility of water contamination, vegetation changes, subsidence, and disturbance from facility operations. Water contamination could result from spills during construction, pipe ruptures, or facility operations. Water contamination can have widespread effects because of the contiguous nature of the wetland habitat used by Whimbrel and other nesting shorebirds. Increased human activity, including air traffic during the year-round operations of the 
proposed Taglu facility, could result in avoidance of even larger areas than predicted under our models.

The relatively simple scenario-modeling approach we developed could also be used to evaluate the relative impacts of different options for development of the MGP. Some factors, such as subsidence, will be similar regardless of the routing of the pipeline, whereas others, such as disturbance effects, could be substantially mitigated through different routing options. Of course, our analyses considered only one species, and an environmental assessment must be based on the overall impacts on all species in the community. These same lowland LCP habitats that were preferred by Whimbrel also supported relatively high densities of nesting shorebirds of several other species, although each had slightly different habitat requirements (PRISM, unpublished data). Expansion of these models to other species could be used in the environmental assessment for estimating the overall impacts of the pipeline on the bird community. This would allow a prediction of the overall impacts under various alternative scenarios. The results could inform decisions as to whether to proceed with the project or, if it does proceed, an assessment of the magnitude of appropriate mitigation measures that might be required to offset adverse impacts.

Responses to this article can be read online at: http://www.ace-eco.org/vol4/iss2/art2/responses/

\section{Acknowledgments:}

Funding and/or logistical support were provided by the Natural Sciences and Engineering Research Council of Canada (NSERC) Northern Research Internship Program and the Polar Continental Shelf Project. We thank Kayla Hansen-Craik, Krista Sittler, and all the Canadian Wildlife Servicel Program for Regional and International Shorebird Monitoring (PRISM) crews for theirinvaluable field assistance.

\section{LITERATURE CITED}

Ashenhurst, A. R. 2004. The effects of seismic lines and drill pads on breeding migratory birds in the Kendall Island Migratory Bird Sanctuary, NWT. Thesis, University of Alberta, Edmonton, Alberta, Canada.

Beyer, H. 2008. Hawth's analysis tools for ArcGIS. Spatialecology.com. [online] URL: http://www.spa tialecology.com/htools/tooldesc.php.

Brown, S., C. Hickey, B. Harrington, and R. Gill. 2001. United States shorebird conservation plan, second edition. Manomet Center for Conservation SciencesManomet, Massachusetts, USA.

Burn, C. 2002. Mackenzie Delta. Pages 24-29 in The Western Arctic Handbook Committee, editor. Natural history of the Western Arctic. Gordon Soules Book Publishers, Seattle, Washington, USA.

Canadian Endangered Species Conservation Council (CESCC). 2006. Wild species 2005: the general status of species in Canada. CESCC, Ottawa, Ontario, Canada.

Canadian Wildlife Service (CWS). 2005. Kendall Island migratory bird sanctuary, Northwest Territories. Pamphlet. CWS, Ottawa, Ontario, Canada.

Definiens Inc. 2009. Understanding images. Website. Definiens Inc., Parsippany, New Jersey, USA. [online] URL: http://www.definiens.com/.

Dickson, H. L., and A. R. Smith. 1991. Use of Landsat Thematic Mapper and multi-spectral scanning imagery to identify habitats and shorebird nesting areas on the outer Mackenzie River Delta, NWT. Pages 91-106 in P. Marsh and C. S. L. Ommanney, editors. Mackenzie Delta: Environmental interactions and implications of development. National Hydrology Research Institute (NHRI) Fourth Symposium, Saskatoon, Saskatchewan, Canada. NHRI, Environment Canada, Ottawa, Ontario, Canada.

Donaldson, G., P. Hyslop, G. Morrison, L. Dickson, and I. Davidson. 2000. Canadian shorebird conservation plan. Canadian Wildlife Service, Environment Canada, Ottawa, Ontario, Canada. 
Emers, M., J. C. Jorgenson, and M. K. Raynolds. 1995. Response of arctic tundra plant communities to winter vehicle disturbance. Canadian Journal of Botany 73:905-917.

Environment Canada. 2007. Mackenzie Gas Project environmental assessment review written submission J-EC-00187. Joint Review Panel Topic Specific Hearing. Topic 18: closing remarks. 28-30 November 2007. [online] URL: http://www.ngps.nt. ca/Upload/Interveners/Environment\% 20Canada/071121 EC\%20Closing\%20Remarks.pdf

Felix, N.A., and M. K. Raynolds. 1989. The effects of winter seismic trails on tundra vegetation in northeastern Alaska, USA. Arctic and Alpine Research 21:188-202.

Geoeye. 2006. IKONOS. Website. Geoeye, Dulles, Virginia, USA. [online] URL: http://geoeye.com/C orpSite/products/imagery-sources/Default.aspx\#ikonos

Godfrey, W. E. 1986. The birds of Canada, revised edition. National Museum of Natural Sciences, Ottawa, Ontario, Canada.

Götmark, F., D. Blomqvist, O. C. Johansson, and J. Bergkvist. 1995. Nest site selection: a trade-off between concealment and view of the surroundings? Journal of Avian Biology 26:305-312.

Gould, J. 1988. A comparison of avian and mammalian faunas at Lake Hazen, Northwest Territories, in 1961-62 and 1981-82. Canadian Field Naturalist 102:666-670

Gratto-Trevor, C. L. 1994. Monitoring shorebird populations in the Arctic. Bird Trends 3:10-12.

Gratto-Trevor, C. L. 1996. Use of Landsat TM imagery in determining important shorebird habitat in the outer Mackenzie Delta, Northwest Territories. Arctic 49:11-22.

Gratto-Trevor, C. L., V. H. Johnston, and S. T. Pepper. 1998. Changes in shorebird and eider abundance in the Rasmussen Lowlands, NWT. Wilson Bulletin 110:316-325.

Gratto-Trevor, C. L., V. H. Johnston and S. T. Pepper. 2001. Evidence for declines in Arctic populations of shorebirds. Bird Trends 8:27-29.
Imperial Oil Resources Ventures Limited. 2007. Response to Natural Resources Canada Information Request, Round 2, Question 2.4, Attachment JRP NRCAN 2.042, Taglu surface subsidence study addendum. Northern Gas Project Secretariat, Yellowknife, Northwest Territories, Canada. [online] URL: http://www.ngps.nt.ca/Upload/Proponent/ Imperial\%200il\%20Resources\%20Ventures\%20Limited/ IORVL R2 NRCAN.pdf

Johnston, V. H., and S. Carrière. 2000. NWT Species Monitoring - Infobase. Resources, Wildlife and Economic Development, Government of the Northwest Territories, Yellowknife, Northwest Territories, Canada. [online] URL: www.enr.gov.nt. ca/ live/pages/wpPages/Infobase.aspx.

Johnston, V. H., C. L. Gratto-Trevor, and S. T. Pepper. 2000. Assessment of bird populations in the Rasmussen Lowlands, Nunavut. Canadian Wildlife Service Occassional Paper No. 101, Environment Canada, Ottawa, Ontario, Canada.

Kemper, J. T. 2006. Vegetation changes on seismic lines from recent (2000-2001) and historic (1970 1986) seismic programs in the Mackenzie Delta area. Environmental Studies Research Funds Report No. 159, Calgary, Alberta, Canada.

Larsen, T., and J. Moldsvor. 1992. Antipredator behavior breeding associations of Bar-tailed Godwits and Whimbrels. The Auk 109:601-608.

Latour, P. B., J. Leger, J. E. Hines, M. L. Mallory, D. L. Mulders, H. G. Gilchrist, P. A. Smith, and D. L. Dickson. 2008. Key migratory bird terrestrial habitat sites in the Northwest Territories and Nunavut. Third Edition. Canadian Wildlife Service. Occasional Paper 114. Environment Canada, Yellowknife, Northwest Territories, Canada.

Lawson, D. E. 1986. Response of permafrost terrain to disturbance: a synthesis of observations from northern Alaska. Arctic and Alpine Research 18:117.

Lillesand, T. M., R. W. Kiefer, and J. W. Chipman. 2004. Remote sensing and image interpretation, fifth edition. Wiley, New York, New York, USA.

Mohren, G. M. J. 2003. Large-scale scenario analysis in forest ecology and forest management. Forest Policy and Economics 5:103-110. 
Morrison, R. I. G. 1997. The use of remote sensing to evaluate shorebird habitats and population on Prince Charles Island, Foxe Basin, Canada. Arctic 50:55-75.

Morrison, R. I. G. 2001. Shorebird population trends and issues in Canada - an overview. Bird Trends 8:1-4.

Natural Resources Canada (NRCan). 2007. Tutorial: fundamentals of remote sensing image interpretation and analysis. Canadian Centre for Remote Sensing, NRCan, Ottawa, Ontario, Canada. http://www.ccrs.nrcan.gc.ca/resource/tutor/fundam/ chapter4/01 e.php

Paehlke, R. 1995. Conservation and environmentalism: an encyclopedia. Routledge, Florence, Kentucky, USA.

Pattie, D. L. 1990. A 16-year record of summer birds on Truelove Lowland, Devon Island, Northwest Territories, Canada. Arctic 43:275-283.

PCI Geomatics. 2005. Geomatica 10 Focus user guide. PCI Geomatics, Richmond Hill, Ontario, Canada. [online] URL: http://www.pcigeomatics.com

Pirie, L. D. 2008. Identifying and modeling Whimbrel Numenius phaeopus breeding habitat in the outer Mackenzie Delta, Northwest Territories. Thesis, Carleton University, Ottawa, Ontario, Canada.

Rees, W. G. 2001. Physical principles of remote sensing. C ambridge University Press, Cambridge, UK.

Ritchie, J. C. 1984. Past and present vegetation of the far northwest of Canada. University of Toronto Press, Toronto, Ontario, Canada.

Skeel, M. A. 1983. Nesting success, density, philopatry, and nest-site selection of the Whimbrel (Numenius phaeopus) in different habitats. Canadian Journal of Zoology 61:218-225.

Skeel, M. A. and E. P. Mallory. 1996. Whimbrel (Numenius phaeopus). In A. Poole and F. Gill. (eds.), The Birds of North America, No. 219. Academy of Natural Sciences, Philidelphia, Pennsylvania, USA, and American Ornithologists' Union, Washington, D.C., USA.
Tarves, T. L. 1987. Shorebirds of the outer Mackenzie Delta, N.W.T./Fish Island area habitat and nest data of the Whimbrel and the Semipalmated Plover. BSc. thesis. Northern Alberta Institute of Technology, Edmonton, Alberta, Canada.

Truett, J. C., R. G. B. Senner, K. Kertrell, R. Rodrigues, and R. H. Pollard. 1994. Wildlife responses to small-scale disturbances in Arctic tundra. Wildlife Society Bulletin 22:17-324.

Working Group on General Status of NWT Species. 2006. NWT Species 2006-2010-General status ranks of wild species in the Northwest Territories. Department of Environment and Natural Resources, Government of the Northwest Territories, Yellowknife, Northwest Territories, Canada. 